\title{
Epidemiology of Viral Hepatitis and Liver Diseases in Pakistan
}

\author{
Amna Subhan Butt
}

\begin{abstract}
Pakistan is among ten most populous countries in world. All sorts of hepatitis are highly prevalent in Pakistan. Due to lack of proper mechanisms to handle sewerage, disinfection and lack of clean water supply across the country, hepatitis A and $E$ are endemic in Pakistan. Moreover, Pakistan ranked in intermediate prevalence zone for hepatitis $B$ and $C$. Also, prevailing socioeconomic conditions, political statuses and unstable healthcare delivery system are not suitable for tackling further progression of hepatitis viruses and its complications. The notable factors related to epidemiology of different hepatitis viruses have been described in this communication.
\end{abstract}

Keywords: Hepatitis in Pakistan, Liver diseases in Pakistan, Hepatitis B and C in Pakistan.

How to cite this article: Butt AS. Epidemiology of Viral Hepatitis and Liver Diseases in Pakistan. Euroasian J Hepato-Gastroenterol 2015;5(1):43-48.

Source of support: Nil

Conflict of interest: None

\section{INTRODUCTION}

Affecting millions of people worldwide, viral hepatitis is a global health problem. The prevalence, most common transmission pathways and pathogenicity of hepatitis vary across the world as well as within countries. Transmitting via exposure to contaminated blood, hepatitis $B$ virus (HBV), hepatitis C virus (HCV) and hepatitis D virus (HDV) leads to chronic hepatitis in majority of cases. ${ }^{1}$ Hepatitis A (HAV) and E (HEV) transmitted primarily via fecal-oral route and mostly resolved after causing acute hepatitis. ${ }^{1}$ Pakistan ranked as a low to middle income country among 22 member states of World health organization $(\mathrm{WHO})$ eastern mediterranean region (EMR). Moreover, with the population of 176.7 million, Pakistan is among 10 most populated countries in the world. Not only in EMRO region but globally as well, Egypt and Pakistan are among the counties where hepatitis are highly prevalent. ${ }^{1}$ Furthermore, there is additional strain on existing health systems due to major social and political upheavals, active or proxy wars in different parts of country, internal displacements of large proportions of persons per population and lack of access to effective healthcare services. Hence, leading to ideal conditions for the spread of hepatitis, especially those spread by contaminated water and lack of sanitation services. ${ }^{2}$

\section{HEPATITIS A AND E INFECTION IN PAKISTAN}

Most of acute hepatitis $\mathrm{A}$ and $\mathrm{E}$ infections remain clinically indistinguishable from other causes of acute viral hepatitis. According to WHO estimates, every year 1.4 million new cases of HAV and 20 million of HEV are reported globally. Approximately, 100,000 people/year and 60,000 people/year die due to acute HAV and HEV infection respectively. However, the attributed mortality rate is even much higher among pregnant women. ${ }^{1,2}$ Unfortunately, there are very few community-based studies and most of the reported evidence regarding prevalence of HAV and HEV in Pakistan are from hospital/clinic-based studies. Hence, there is variation in the reported statistics. However, it has been that HAV and HEV are endemic in Pakistan.

Hepatitis A accounts for 50 to $60 \%$ of acute viral hepatitis in children of Pakistan. Attributed to early exposure, almost $96 \%$ of individuals are found to be exposed (HAV IgG reactive) to HAV by the age of 5 years. ${ }^{3,4}$ On the other hand, HAV leads to acute hepatitis in 3.5 to $4 \%$ of adults and approximately 98 to $100 \%$ adults are exposed to HAV at adulthood. ${ }^{5}$ Acute HAV infection is usually subclinical or resolve without complications. However, in a series of 2,735 confirmed cases of acute HAV, reported from 1991 to 1998 from a

Department of Medicine, Aga Khan University Hospital, Karachi, Pakistan

Address reprint requests to: Amna Subhan Butt, Assistant Professor, Department of Medicine, Aga Khan University Hospital, Karachi Pakistan, e-mail: amna.subhan@aku.edu 
Tertiary Care Hospital of Pakistan, 232 children required hospitalization and of these $36.7 \%$ died. ${ }^{6}$ These findings supports need of improved sanitation, provision of clean water and early vaccination of children for HAV in countries like Pakistan. These measures will be helpful in reducing morbidity and mortality associated with HAV (Table 1).

Being a most common cause of acute hepatitis in adults, $\mathrm{HEV}$ is responsible for acute hepatitis in 20 to $22 \%$ among adults and $2.4 \%$ among children. ${ }^{3}$ Past exposure to HEV has been reported in 1.4 to $19.4 \%$ children and 16 to $20 \%$ of healthy adults. ${ }^{3,4,7}$ Due to the fecal contamination of water, mini outbreaks have been reported mostly during summers, rain and floods with attack rate ranging 10 to 20 (Table 2). ${ }^{3,8,9}$ The overall mortality rate due to acute hepatitis E ranges 0.4 to $4.0 \%$; however, mortality rate gets much higher in the presence of pregnancy (16-33\% $)^{10,11}$ and incase of acute liver failure with HEV in the presence of chronic liver disease. So far, HEV genotype 1 has been reported as the dominant genotype in Pakistan with isolates Sar-55 (87-Pakistan-A), Abb-2B (88-Pakistan-2B) and $87-$ Pakistan-B. ${ }^{12}$ Contamination of sewerage with water resources has a major role in HEV spread in Pakistan. In a recent study, 86 raw sewerage samples were collected from different outlets of Islamabad (capital of Pakistan) and Rawalpindi (neighboring city to Islamabad). Out of these 19(44.7\%) samples from Rawalpindi and $16(41.02 \%)$ from Islamabad were HEV positive. All of HEV positive samples were from the highly congested areas of two cities. ${ }^{13}$ These findings clearly suggest that the lack of proper mechanism to handle sewerage and disinfection is a leading factor for spread of HEV.

\section{HEPATITIS B, C AND D IN PAKISTAN}

Hepatitis B and C are responsible for $>75 \%$ of cirrhosis and hepatocellular carcinoma (HCC) in WHO EMRO region. ${ }^{2}$ Variable prevalence estimates has been reported in various studies from Pakistan which is most probably due to differences in study design, sample size, study settings and exposure to various risk factors. Most of the studies have reported HCV prevalence among children between 0.4 and $1.4 \%$ except one study from Myo

Table 1: Hepatitis A in Pakistan ${ }^{3,4,30}$

\begin{tabular}{lll}
\hline & Anti-HAV IgG (\%) & Anti-HAV IgM (\%) \\
\hline $\begin{array}{l}\text { Healthy children } \\
\begin{array}{l}\text { Children with sub- } \\
\text { Clinical hepatitis }\end{array}\end{array}$ & $82-100$ & - \\
$\begin{array}{l}\text { Children with acute } \\
\text { viral hepatitis }\end{array}$ & - & - \\
$\begin{array}{l}\text { Healthy adults } \\
\begin{array}{l}\text { Adult patients with } \\
\text { acute viral hepatitis }\end{array}\end{array}$ & - & 52 \\
\hline
\end{tabular}

Hospital, Lahore, where out of 538 healthy children, $4.0 \%$ were found to have reactive anti-HCV antibody. ${ }^{3,14-16}$ The prevalence of HBV ranged between 1.9 and 3.6\% among healthy children (Table 3). ${ }^{3,4}$

Among adults several cross-sectional studies have been conducted that revealed prevalence of HBV 2.2 to $11.9 \%$ in healthy individuals. Relatively lower HBV prevalence was found among individuals who were screened prior to employment in armed forces (3-7.3\%) and healthy blood donors (0.8-5.8\%). A wide variability in HBV prevalence estimates has been observed among pregnant women, i.e. 1.6 to $12.0 \%$. Being at risk healthcare workers had higher HBV prevalence that ranged from 2.4 to $20 \%$ with the dentists $(17 \%)$ and housekeeping $(20 \%)$ staff being the most affected one. The estimated HBV prevalence was alarming among high-risk individuals like commercial sex workers $(11.6 \%)$, individuals with thalassemia/hemophilia (4-8.4\%), those who were on regular hemodialysis $(6.9-12.4 \%)$, prisoners $(5.9 \%)$ and drug addicts (22.8\%). ${ }^{3,15}$ The most common HBV genotype in Pakistan is genotype D (65-96.2\%) followed by genotype $C$. $^{3,17}$

The overall prevalence of $\mathrm{HCV}$ among volunteer blood donors and healthy adults ranged between 0.2 and $6.5 \%$ and 2.1 to $13.5 \%$ respectively. As compared to HBV, the $\mathrm{HCV}$ prevalence was found much higher among pregnant women (3.2-18.2\%). Those who had recurrent exposure to blood or blood products like those who have thalassemia/ hemophilia (25-56.8\%) and those who are hemodialysis dependent (20-24.7\%) were found to have highest HCV prevalence which is very alarming. ${ }^{3,15,16}$ Owing to high-

Table 2: Hepatitis E in Pakistan $3,4,7,30-32$

\begin{tabular}{|c|c|c|}
\hline & $\begin{array}{l}\text { Anti-HEV IgG/ } \\
\text { total+ (\%) }\end{array}$ & $\begin{array}{l}\text { Anti-HEV } \\
\text { IgM+ (\%) or } \mathrm{n}\end{array}$ \\
\hline Healthy children & $18.3,19.4$ & - \\
\hline $\begin{array}{l}\text { Children from low socio- } \\
\text { economic urban communities }\end{array}$ & $1.4,14.4$ & 2.4 \\
\hline Healthy adults & $16.0,20$ & - \\
\hline $\begin{array}{l}\text { Hospitalized patients with } \\
\text { jaundice/acute hepatitis }\end{array}$ & $7-22.0$ & 20.2 \\
\hline $\begin{array}{l}\text { PAF bases Karachi, outbreak of } \\
\text { acute hepatitis }\end{array}$ & - & $\begin{array}{l}204 \text { confirmed } \\
\text { cases }\end{array}$ \\
\hline $\begin{array}{l}\text { G-10 Islamabad, outbreak of } \\
\mathrm{HEV} \text { in general public }\end{array}$ & - & $3827,10.0 \mathrm{AR}$ \\
\hline $\begin{array}{l}\text { Lahore Garrison, Outbreak of } \\
\text { HEV in army people }\end{array}$ & - & 283 confirmed \\
\hline $\begin{array}{l}\text { Military Unit Abbottabad, } \\
\text { outbreak of hepatitis } E \text { in } \\
\text { military unit }(n=109)\end{array}$ & - & 95.0 \\
\hline $\begin{array}{l}\text { Hospital acquired outbreak, } \\
\text { Karachi }(\mathrm{N}=113)\end{array}$ & - & AR 15.9 \\
\hline $\begin{array}{l}\text { Pregnant women with jaundice/ } \\
\text { acute hepatitis }\end{array}$ & $57.0,61$ & 66.9 \\
\hline HEV superinfection in CLD & 17.5 & - \\
\hline
\end{tabular}


Table 3: Hepatits B virus and HCV in Pakistan $3,15,16,24$

\begin{tabular}{lll}
\hline & $H B s g^{+}(\%)$ & $\begin{array}{l}\text { Anti-HCV+ } \\
(\%)\end{array}$ \\
\hline $\begin{array}{l}\text { Healthy children } \\
\text { Healthy adult recruits in }\end{array}$ & $1.9-3.6$ & $0.4-1.4$ \\
armed forces & $3-7.3$ & $2.2-5.2$ \\
Blood donors & $0.8-5.8$ & $0.2-6.5$ \\
Healthy adults/ & $2.2-11.9$ & $2.1-13.5$ \\
general population & & \\
Pregnant women & $1.6-12$ & $3.2-18.2$ \\
Spouses of index patients & - & $4.3-5.1$ \\
Healthcare workers & $2.4-20$ & $4-10$ \\
Commercial sex workers & 11.6 & 12.3 \\
Thalassemia/hemophilia & $4-8.4$ & $25-56.8$ \\
Dialysis & $6.9-12.4$ & $20-24.7$ \\
Chronic liver disease & $10-46.67$ & $40-86.0$ \\
Hepatocellular carcinoma & 25.35 & 57.99 \\
\hline
\end{tabular}

risk behavior prisoners were also found to have high $\mathrm{HCV}$ prevalence, i.e. $15.2 \%{ }^{18}$ Majority of patients $(>80 \%)$ are infected by HCV genotype 3. Other relatively common $\mathrm{HCV}$ genotypes are 2 and $1.3,16$

Considering the significant burden of $\mathrm{HBV}$ and $\mathrm{HCV}$ differences in reported estimates from different areas of Pakistan, first national survey was conducted during 2007 to 2008, to estimate prevalence of hepatitis B and $\mathrm{C}$ in general population of Pakistan..$^{19}$ A total of 47,043 individuals were screened. The overall prevalences of $\mathrm{HBV}$ and $\mathrm{HCV}$ were 2.5 and $4.8 \%$ respectively, reflected a combined infection rate of $7.6 \%$ in the general population. Increasing age and being married, exposure to therapeutic injections, hospitalization, and shave by barbers were the factors associated with higher risk of acquiring HBV and HCV. Among all four provinces, the highest HCV prevalence was found in Punjab (6.7\%) and Sindh (5.0\%) which was even much higher $(12-13 \%)$ in certain cities of both provinces. The highest prevalence of $\mathrm{HCV}$ was found in Balochistan (4.3\%) followed by Sindh (2.5\%).

Hepatitis D is another challenge for healthcare providers in Pakistan. Hepatitis D virus could present as coinfection or superinfection with HBV. In an earlier study of 408 patients with hepatitis B-related chronic liver disease, 44 and $1.4 \%$ patients had HDV superinfection and coinfection respectively. ${ }^{20}$ Based upon presence of anti-HDV antibody, the prevalence of HDV was found 16.6 to $35.2 \%$ in subsequent studies. ${ }^{21,22}$ Mumtaz et al compared BV/HDV coinfection with HBV monoinfection. In comparison to HBV mono-infection, HBV/ HDV coinfection was associated with higher ALT levels, suppressed HBV DNA levels, HBeAg negative disease and more aggressive liver disease including cirrhosis. ${ }^{22}$

According to WHO estimates up to $75 \%$ of therapeutic injections received in southeast Asia are unsafe. The scenario applies well to Pakistan where syringes are reused and sterility of injections is often not maintained, hence, play a major role in spread of $\mathrm{HBV} / \mathrm{HCV}$. In Pakistan, approximately 1.5 million units of blood products are transfused every year. Unfortunately, the standardized practices in provision of safe blood products are not followed by all blood banks, leading to spread of hepatitis B, C and D. Exposure to contaminated instruments or blood during minor/major surgeries, sharing sharps like razors, males getting their shave from communal barber, prior hospitalizations, injections drug use, body piercing, perinatal transmission, high risk sexual behavior are the other factors identified attributing to the spread of hepatitis B, C and D. . $^{15,16,19,23}$

\section{ACUTE HEPATITIS, CHRONIC LIVER DISEASE AND HEPATOCELLULAR CARCINOMA IN PAKISTAN}

In case series reported from one of the largest government sector Tertiary Care Hospital of Karachi, Pakistan, the authors analyzed 5,193 cases fulfilling all criteria of viral hepatitis and admitted during 1987 to $2007 .^{5}$ Out of these, $6.7 \%$ had acute hepatitis, $44.1 \%$ had chronic hepatitis, $27.5 \%$ had cirrhosis and $20.8 \%$ were $\mathrm{HBV} / \mathrm{HCV}$ carriers. Hepatitis C was found to be the most common (55.8\%) viral hepatitis, associated with chronic hepatitis and cirrhosis followed by hepatitis B $(32.6 \%)$. Hepatitis B was seen a decade earlier than hepatitis $\mathrm{C}$. Over decades a rising trend in $\mathrm{HCV}$ and declining evidence of hepatitis B was observed which could be due to increased awareness and detection of hepatitis $C$ and efforts for HBV vaccination in Pakistan. Likewise, data from other studies revealed 40 to $86 \%$ and 10 to $46 \%$ cases of chronic liver disease are attributed to hepatitis $\mathrm{C}$ and B respectively. $3,15,16$

Hepatocellular carcinoma is a leading cause of cancerrelated mortality. Based upon data from selected, local cancer registries from Pakistan, HCC was found to be the third most common cancer in men (age standardized rate $12.3 / 100,000)$ and the seventh most common cancer in women (ASR 3.1/100,000). ${ }^{24}$ Unfortunately, most of the studies available from Pakistan are hospital-based case series with small sample size; hence true prevalence and incidence rate of HCC could not be ascertained. Recently, Butt et $\mathrm{al}^{24}$ have reported an aggregated analysis of 3,319 cases from 29 studies. The HCC was attributed to HCV in $57.99 \%$, HBV in $25.35 \%$, HBV/HCV coinfection in $5.26 \%$ cases. Additionally, HBV/HDV and HBV/HDV/HCV coinfections were found in approximately $2 \%$ cases. Beside a consistent rising trend in number of HCC cases reported, a clear shift was observed in etiological factors leading to HCC. From the 1970s till the mid 1990s, 
hepatitis B was the most common etiological factor for HCC which was replaced by HCV afterwards. This is might due to the rising incidence of DM and metabolic syndrome that increasing number of viral marker negative HCC has been reported over the period of time. In the largest study reported from Pakistan, out of 645 HCC cases, $15.3 \%$ were viral marker negative. ${ }^{25}$ Unfortunately, majority (62.8\%) of patients had advanced HCC on presentation, diagnosed when symptomatic. Moreover, HBVHCC and viral marker negative HCCs were found to be more advanced and aggressive at the time of presentation. Compliance with surveillance was found poor in case of nonviral HCC.

\section{EFFORTS TO CONTROL HEPATITIS B AND C IN PAKISTAN}

1. Establishment of a viral hepatitis surveillance system: In 2005, Ministry of Health (MOH) has launched a National Program for Hepatitis Prevention and Control (NPHPC) which was mainly dealing with HCV and had many limitations. In collaboration with CDC's Division of Viral Hepatitis, Pakistan Field Epidemiology and Laboratory Training Program (FELTP) established a hepatitis sentinel surveillance system in five large public hospitals in four provinces and Islamabad capital territory in 2009. Field epidemiology and laboratory training program is housed at National Institute of Health in Islamabad. ${ }^{26}$ From June 2013 to December 2014, out of 7,387 suspected cases, 3,008 had viral hepatitis. The newly reported $\mathrm{HCV}$ cases were $65 \%$. Hepatitis E, B was found in 12, 18, 31.4 and 2.3\% cases respectively. Majority of HAV or HEV-infected patients were 6 to 30 years of age. While those who had hepatitis B or C were comparatively older. ${ }^{26,27}$

2. Prime Minister's program for the prevention and control of hepatitis viral infections: Considering heavy burden and huge cost, the Prime Minister's Program for the prevention and control of hepatitis viral infections was launched for 5 years from 2005 to 2010, to support treatment of hepatitis $B$ and $C$ for nonaffording patients. A total of 7,752 patients were treated at the 12 sites for hepatitis C. Only $45.4 \%$ patients completed 6 months of interferon and ribavirin therapy and end of treatment response was available in $49 \%$ cases. Approximately, 67\% had EOTR and 33\% were nonresponders. Data for hepatitis B were collected from eight sites. A total of 454 cases received treatment and $85(18.72 \%)$ fulfilled the criteria for treatment. Treatment was completed by nine (10.58\%) cases, with three (3.52\%) cases showing Hepatitis B 'e' antigen clearance and anti-HBe production. ${ }^{28}$ However, proper planning and accountability lack in this program. Inadequate clinical follow-up and inadequate documentation of serological/biochemical tests were the major drawbacks, hence, leading to inadequate assessment of treatment response, failure to complete treatment, resulting in wastage of huge human and financial resources.

3. Immunization for HBV: The HBV prevalence among children $<5$ years of age has been found quite high which is probably due to vertical transmission. A tetravalent vaccine (with DPT) HBV vaccine was incorporated in Pakistan's EPI in 2001. It was later replaced with the pentavalent vaccine (DPT, $\mathrm{HBV}, \mathrm{Hib})$ given at 6, 10 and 14 weeks without a birth dose. In a recent study mothers and their children aged 6 to 36 months were tested for $\mathrm{HBV}$ to assess the risk of HBV transmission in infants born to $\mathrm{HBV}$ positive mothers in Pakistan. ${ }^{29}$ Children born to HBsAg positive mothers had higher prevalence of HBV (14.6\%) as compared to $\mathrm{HBsAg}$ negative mothers (2.1\%). Moreover, $\mathrm{HBV}$ transmission rate to infants was found $5.4 \%$ by 12 months of age when mother was HBeAg positive. Despite provision of facility for HBV vaccination in Prime Minister Program for adults, heathcare providers, the vaccine coverage is low. This may be due to lack of awareness at community level or inability to access the facility.

4. Other measures: To increase awareness, certain measures have been taken at government and community level. To improve awareness and to establish partnerships, government has funded other viral hepatitis public awareness campaigns since January 2011 and held events for World Hepatitis Day 2012 and later. Many NGOs, GI and liver disease societies conduct seminars, mass campaigns to educate community and healthcare providers. Antiviral therapies for HBV (interferon alpha, pegylated interferon, lamivudine and entecavir) and HCV (interferon alpha, pegylated interferon and ribavirin) are on the national essential medicines list or subsidized by the government. A standard definition for hepatitis has been defined. However, beside recently established FELTP, there is no system for routine surveillance and reporting of outbreaks, mortalities due to hepatitis, liver disease and HCC.

\section{CONCLUSION}

Burden of hepatitis and its complications are a huge challenge for government and healthcare providers in Pakistan. Majority of patients remain asymptomatic, leading to silent epidemic. Measures for prevention and 
control of hepatitis can, therefore, make a significant contribution in reducing the disease burden and saving lives. A high proportion of patients approach private hospitals for treatment and bear heavy cost for their treatment. Public health services system constitutes the only source of care available for the nonaffording patients. Prime Minister's program for the prevention and control of hepatitis viral infections is a unique program in the region. However, most of the efforts and resources were utilized in treatment rather than prevention and the program is victimized by poor planning and lack of quality control measures. The cost to treat patients with chronic HBV or HCV infection far outweighs the cost of implementing prevention programs. A comprehensive strategy is urgently needed to prevent transmission of these blood-borne pathogens. There is an urgent need to implement National Blood Policy regarding provision of safe blood products, to organized transfusion network, to establish surveillance system to report blood born infections, standardization and regulation of appropriate blood screening procedures. Public awareness campaigns are needed to educate people and even healthcare providers about factors associated with spread of hepatitis, especially to avoid reuse of therapeutic injections, sharps like razors, etc. Measures are needed to rehabilitate IDUs, implementation of steps like needle exchange program and vaccination for $\mathrm{HBV}$ at least. Hepatitis B virus vaccination should be provided at birth and measures are needed to improve HBV vaccine coverage. Strategies to improve safe, clean water supply and to improve sewerage system are imperative in prevention of HAV, HEV. Hence, it is a long journey and huge efforts are needed to reduce burden of hepatitis and its complication in Pakistan.

\section{REFERENCES}

1. WHO. Global Alert and Response (GAR): Global policy report on the prevention and control of viral hepatitis in WHO Member States; 2013. Available at: (http://www.who. $\mathrm{int} / \mathrm{csr} /$ disease/hepatitis/global_report/en/. Accessed on: 1 november 2014) Contract No.: Document Number.

2. WHO. Hepatitis. World Health Organization Regional Office for the Eastern Mediterranean [online factsheet]. Available at: (http://www.emro.who.int/health-topics/hepatitis/index. html/. Accessed on 1 November 2014.

3. Bosan A, Qureshi H, Bile KM, Ahmad I, Hafiz R. A review of hepatitis viral infections in Pakistan. J Pak Med Assoc 2010 Dec;60(12):1045-1058.

4. Aziz S, Muzaffar R, Hafiz S, Abbas Z, Zafar MN, Naqvi SA, et al. Helicobacter pylori, hepatitis viruses A, C, E, antibodies and HBsAg - prevalence and associated risk factors in pediatric communities of karachi. J Coll Physicians Surg Pak 2007 Apr;17(4):195-198.
5. Ahmed W, Qureshi H, Arif A, Alam SE. Changing trend of viral hepatitis: a twenty one year report from Pakistan Medical Research Council Research Centre, Jinnah Postgraduate Medical Centre, Karachi. J Pak Med Assoc 2010 Feb;60(2): 86-89.

6. Shah U, Habib Z, Kleinman RE. Liver failure attributable to hepatitis A virus infection in a developing country. Pediatrics 2000 Feb;105(2):436-438.

7. Jafri W, Yakoob J, Abid S, Awan S, Siddiqui S, Jafri F, et al. Seroprevalence of hepatitis E and Helicobacter pylori in a low socioeconomic area of a metropolitan city in a developing country. Br J Biomed Sci 2013;70(1):27-30.

8. Rab MA BM, Mubarik MM, et al. Waterborne hepatitis E virus epidemics in Islamabad, Pakistan: a common source of outbreak traced to the malfunction of a modern water treatment plant. Am J Trop Med Hyg 1997;57(2):151-157.

9. Bryan JP, Iqbal M, Tsarev S, Malik IA, Duncan JF, Ahmed A, et al. Epidemic of hepatitis E in a military unit in Abbotrabad, Pakistan. Am J Trop Med Hyg 2002 Dec;67(6):662-668.

10. Iqbal S, Umar M, SM. Acute hepatitis E: experience at Holy Family Hospital, Rawalpindi Pak J Gastroenterol 2006;20:32-36.

11. Yasmeen T, Hashmi HA, Taj A. Fetomaternal outcome with hepatitis e in pregnancy. J Coll Physicians Surg Pak 2013; 23(10):711-714.

12. Iqbal $\mathrm{T}$, Idrees $\mathrm{M}$, Ali L, Hussain A, Ali M, Butt $\mathrm{S}$, et al. Isolation and characterization of two new hepatitis $E$ virus genotype 1 strains from two mini-outbreaks in Lahore, Pakistan. Virol J 2011 Mar 4;8:94.

13. Ahmad T, Waheed Y, Tahir S, Safi SZ, Fatima K, Afzal MS, et al. Frequency of HEV contamination in sewerage waters in Pakistan. J Infect Dev Ctries 2010 Dec;4(12):842-845.

14. HI K. A study of seroprevalence of hepatitis B and C in mothers and children in Lahore. Pak Pediatr J 1996;20:163-166.

15. Ali SA, Donahue RM, Qureshi H, Vermund SH. Hepatitis B and hepatitis $C$ in Pakistan: prevalence and risk factors. Int J Infect Dis 2009 Jan;13(1):9-19.

16. Jafri W, Subhan A. Hepatitis C in Pakistan: magnitude, genotype, disease characteristics and therapeutic response. Trop Gastroenterol 2008 Oct-Dec;29(4):194-201.

17. Mumtaz K, Hamid S, Ahmed S, Moatter T, Mushtaq S, Khan A, et al. A study of genotypes, mutants and nucleotide sequence of hepatitis B virus in Pakistan: HBV genotypes in Pakistan. Hepat Mon 2011 Jan;11(1):14-18.

18. Butt A, Jafri W, Janjua N, Pasha O, editors. Seroprevalence and Risk Factors for Hepatitis C Infection among Male Prisoners in Karachi, Pakistan. Am J Gastroenterol 2010. Nature Publishing Group 75 Varick St, 9th flr, New York, NY 10013-1917 USA.

19. Qureshi H, Bile KM, Jooma R, Alam SE, Afridi HUR. Prevalence of hepatitis B and $C$ viral infections in Pakistan: findings of a national survey appealing for effective prevention and control measures. East Mediterr Health J 2010;16(Suppl):15-23.

20. Zuberi S. An overview of HBV/HCV in Pakistan. Pak J Med Res 1998;37(Suppl):12.

21. Mumtaz K, Hamid SS, Adil S, Afaq A, Islam M, Abid S, et al. Epidemiology and clinical pattern of hepatitis delta virus infection in Pakistan. J Gastroenterol Hepatol 2005 Oct;20(10): 1503-1507.

22. Mumtaz K, Ahmed US, Memon S, Khawaja A, Usmani MT, Moatter T, et al. Virological and clinical characteristics of hepatitis delta virus in South Asia. Virol J 2011;8:312. 
23. Qureshi H, Arif A, Riaz K, Alam SE, Ahmed W, Mujeeb SA. Determination of risk factors for hepatitis B and C in male patients suffering from chronic hepatitis. BMC Res Notes 2009 Oct 23;2:212.

24. Butt AS, Abbas Z, Jafri W. Hepatocellular carcinoma in Pakistan: where do we stand? Hepat Mon 2012 Oct;12(10 HCC):e6023.

25. Butt AS, Hamid S, Wadalawala AA, Ghufran M, Javed AA, Farooq O, et al. Hepatocellular carcinoma in Native South Asian Pakistani population; trends, clinicopathological characteristics \& differences in viral marker negative and viralhepatocellular carcinoma. BMC Res Notes 2013 Apr 8;6:137.

26. Centers for Disease C, Prevention. Establishment of a viral hepatitis surveillance system-Pakistan, MMWR Morbidity and mortality Weekly Report 2009-2011;60(40):1385.

27. Feltp-Pakistan. Acute Viral Hepatitis Sentinel Surveillance System Pakistan. In press June 2010 till December 2013.
28. QureshiH,MohamudBK,AlamSE,ArifA,AhmedW.Treatment of hepatitis B and C through national programme-an audit. J Pak Med Assoc 2013 Feb;63(2):220-224.

29. Qureshi H, Javaid N, Alam SE, Bile KM. The evidence of mother to child transmission of hepatitis $B$ virus infection in Pakistan and the need for hepatitis B immunization policy change. J Pak Med Assoc 2014 Apr;64(4):403-408.

30. Ahmed W, Qureshi H, Arif A, Alam SE. Changing trend of viral hepatitis: a twenty one year report from Pakistan Medical Research Council Research Centre, Jinnah Postgraduate Medical Centre, Karachi. J Pak Med Assoc Feb;60(2):86-89.

31. Siddiqui AR, Jooma RA, Smego RA, Jr. Nosocomial outbreak of hepatitis E infection in Pakistan with possible parenteral transmission. Clin Infect Dis 2005 Mar 15;40(6):908-909.

32. Hamid SS, Atiq M, Shehzad F, Yasmeen A, Nissa T, Salam A, et al. Hepatitis $\mathrm{E}$ virus superinfection in patients with chronic liver disease. Hepatology 2002 Aug;36(2):474-478. 